\title{
UV-Vis Spectroscopy to Enable Determination of the Dissolution Behavior of Solid Dispersions Containing Curcumin and Piperine
}

\author{
Yosi Bayu Murti ${ }^{1}$, Yustina Sri Hartini ${ }^{2}$, Wouter Leonardus Joseph Hinrichs ${ }^{3}$, Henderik Willem Frijlink ${ }^{3}$, Dewi Setyaningsih ${ }^{2 *}$ \\ 'Faculty of Pharmacy, Universitas Gadjah Mada, INDONESIA. \\ ${ }^{2}$ Faculty of Pharmacy, Sanata Dharma University, INDONESIA. \\ 3Department of Pharmaceutical Technology and Biopharmacy, University of Groningen, THE NETHERLANDS.
}

\begin{abstract}
Objective: Curcumin and piperine exibit poor aqueous solubility and dissolution. Solid dispersion technology is a promising way to improve dissolution of lipophilic compounds. Therefore, to investigate the dissolution behavior, an accurate determination of curcumin and piperine concentrations in a sample containing $0.5 \mathrm{wt}-\%$ SLS in sodium phosphate buffer as the dissolution medium was required. The goal of research was to investigate whether UV-Vis spectroscopy can be used to accurately determine curcumin and piperine concentrations in aqueous solutions. Method: Stock solutions (1 $\mathrm{mg} / \mathrm{mL})$ of curcumin and piperine were prepared in methanol. A series of solutions for calibration were prepared by mixing the stock solutions in various ratios after which they were diluted with dissolution medium (0.5\%-wt sodium lauryl sulfate in $20 \mathrm{mM}$ phosphate buffer; $\mathrm{pH}$ 6.0). Solutions of curcumin $(2 \mu \mathrm{g} / \mathrm{mL})$ and piperine $(1 \mu \mathrm{g} / \mathrm{mL}$ were subjected to overlay scan in a UV-VIS spectrophotometer in each $\lambda_{\max }$ of 430 and $335.5 \mathrm{~nm}$ for curcumin and piperine, respectively. The method was validated according $\mathrm{ICH}$ requirements, such as specificity, linearity, accuracy, precision, limit of detection and limit of quantification. Results:
\end{abstract}

At a concentration range of 0.1 to $5 \mu \mathrm{g} / \mathrm{mL}$, calibration curves of curcumin and piperine showed linearity with $R^{2}=0.9980$ and 0.9982 , respectively. Precision and accuracy was confirmed by AOAC. Furthermore, LOD of both compounds was $0.23 \mu \mathrm{g} / \mathrm{mL}$ and LOQ of curcumin and piperine was 0.72 and $0.69 \mu \mathrm{g} / \mathrm{mL}$, respectively. Conclusion: UV-Vis spectroscopy can be used to accurately determine curcumin and piperine concentrations in dissolution samples obtained during screening the dissolution behavior of solid dispersions containing these compounds.

Key words: Curcumin, Piperine, Dissolution, UV-Vis spectroscopy

Correspondence

Dewi Setyaningsih, Faculty of Pharmacy, Sanata Dharma University, INDONESIA.

Phone: +62 82135993494

Email: dewi@usd.ac.id

DOI: 10.5530/jyp.2019.11.6

\section{INTRODUCTION}

Curcumin is the principle component of turmeric rhizome and exhibits various pharmacological activities, such as antiinflammatory, antioxidant, hepatoprotector, antibacterial and anticancer activity. ${ }^{1-3}$ Despite having excellent biological activity in vitro and in vivo, clinical application of this natural compound as a pharmaceutical agent is hampered because of its poor bioavailability after oral administration. ${ }^{4,5}$ The poor bioavailability of curcumin can be ascribed to two reasons. First, curcumin exhibits an aqueous solubility of only $11 \mathrm{ng} / \mathrm{mL},{ }^{6}$ causing poor dissolution behavior in the gastrointestinal tract, by which only limited amount of dissolved molecules are available for absorption. E.g. in a publication of Wahlström et al. it was reported that $75 \%$ of the administered dose of curcumin was found in faeces indicating that curcumin was poorly dissolved in the gastrointestinal milieu. ${ }^{7}$ Second, once dissolved, curcumin is rapidly metabolized into curcumin glucuronate by UDP-glucuronosyltransferase. $^{8}$

In Indonesian traditional medicine, a combination of turmeric and black pepper extract has been used in therapy. ${ }^{9}$ It was believed that additional of black pepper extract, which predominately contains piperine, enhances the efficacy of turmeric extract. Scientific research has meanwhile supported the rational basis of the enhanced efficacy of the combination: co-administration of piperine enhances curcumin's bioavailability. ${ }^{10}$ Another study showed that piperine is a UDP-glucuronosyltransferase inhibitor in both the small intestine and liver. ${ }^{11}$ Furthermore, piperine has been reported to increase bioavailability as it also acts as a P-glycoprotein inhibitor in the gastrointestinal tract. Also a synergistic effect of piperine-curcumin has been found. An in vivo study in rats revealed that co-administration with piperine improved the antiiflammatory effect. In addition, piperine alone demonstrated antiinflammatory, analgesic, antineoplastic, axiolytic activity and stimulator of digestive enzyme. ${ }^{12}$

Similar to curcumin, piperine also exhibits a poor aqueous solubility. Therefore, in studying such combination the low aqueous solubility of both of these two compounds needs to be addressed. Solid dispersion technology is an often applied strategy to improve the dissolution behaviour of poorly soluble drugs. ${ }^{13}$ Therefore, in order to deal with the low aqueous solubility and to prepare a synergistic combination, which is expected to improve curcumin bioavailability in the pre-clinical study, we prepared microparticle based solid dispersion containing both curcumin and piperine.

To evaluate this strategy, studying the in vitro dissolution behavior is being the first step in screening formulations. To be able to do so, an accurate and reliable analytical method is needed to determine both curcumin and piperine concentration. Furthermore, since dissolution experiments often involve large number of samples, rapid and economical analytical method is required.

Several analytical methods have been reported to quantify curcumin in the co-mixed curcumin-piperine. As in a methanolic solution, piperine 
and curcumin exhibit a $\lambda_{\max }$ of 341 and $420 \mathrm{~nm}$, respectively, it can be expected that both compounds will interfere each other during analysis by spectrophotometry method as the peaks may overlap. Therefore, the reported analytical methods are based on chromatography, i.e. Liquid Chromatography-Mass Spectrometry (LC-MS), ${ }^{14}$ High Performance Liquid Chromatography (HPLC), ${ }^{10,15,16}$ Ultra-Fast Liquid Chromatography ${ }^{17}$ and High Performance Thin Layer Chromatography (HPTLC). ${ }^{18}$ Although chromatographic method is suitable for selectively determine both curcumin and piperine concentrations, the reported methods require laborious sample extraction procedures by which it may potentially affect negatively to the samples since curcumin degradation may occur due to inevitably light exposure. ${ }^{19}$ However, UV-Vis spectroscopic method has been reported to be suitable to determine concentration of curcumin/piperine/quercetin in an Ayurvedic polyherbal formulation..$^{20}$ Using a particular calculation involving the absorptivity of the tested compounds, the concentration of the compounds in a co-mixture could be accurately determined. ${ }^{21}$ In the current study, we aimed at validating a spectroscopic method for curcumin/piperine quantification from samples collected directly from the dissolution experiment where dissolution medium is present, which differs from the sample reported before. ${ }^{21}$ Therefore, the novelty of this study is in developing a spectroscopic based analytical method to estimate curcumin and piperine in dissolution medium using combinatorial equation.

\section{MATERIALS AND METHODS}

\section{Materials}

Curcumin as reference standard was purchased from Nacalai, Japan. C. longa standardized extract (97.56\%) was supplied by PT Phytochemindo Reksa, Bogor, Indonesia. Piperine was isolated and purified as described before, ${ }^{22,23}$ after which it was further characterized based on piperine standard (Sigma Aldrich) using Thin Layer Chromatography method. Sodium dihydrogen phosphate and Sodium Lauryl Sulfate (SLS) were purchased from Merck, Darmstadt, Germany. Mili Q water was prepared in our laboratory. All solvents were of analytical grade and were purchased from Merck, Darmstadt, Germany. Dissolution medium consisting of $0.5 \mathrm{wt}-\%$ SLS in $20 \mathrm{mM}$ sodium phosphate buffer of $\mathrm{pH} 6.0$ was prepared in our laboratory.

\section{Method}

\section{Determination of $\lambda_{\max }$}

Solutions of curcumin $(2 \mu \mathrm{g} / \mathrm{mL})$ and piperine $(1 \mu \mathrm{g} / \mathrm{mL})$ prepared in dissolution medium was subjected to overlay scan in a UV spectrophotometer from 200-600 nm. It was confirmed that $\lambda_{\max }$ for curcumin and piperine are of 430 and $335.5 \mathrm{~nm}$, respectively. Additionally, as a control, solutions of curcumin and piperine in methanol at the same concentrations were also scanned. The $\lambda_{\max }$ for curcumin and piperine in methanol was 420 and $341 \mathrm{~nm}$.

\section{Preparation of calibration curve}

Curcumin or piperine stock solutions were prepared in methanol at a concentration of $1.0 \mathrm{mg} / \mathrm{mL}$. Series of solutions containing curcumin and piperine at various concentrations were prepared by spiking the dissolution medium with the stock solutions. The calibration curves were prepared at concentrations of $0.05-5 \mu \mathrm{g} / \mathrm{mL}$ for curcumin and piperine, respectively. Curcumin and piperine were simultaneously analyzed. Analyte concentrations were calculated based on combination calculation from the two $\lambda$ measurements. Linearity of concentration and absorption and significance of the regressions were analyzed using Least Square Analysis method. The experiments were done in triplicate.

\section{Simultaneous equation for determination of curcumin/piperine}

The equations (equation 1,2) were derived based on the absorption of curcumin and piperine at the each maximum wavelength. Two wavelengths were selected ( $335 \mathrm{~nm}$ for curcumin and $430 \mathrm{~nm}$ for piperine) to calculate the concentrations based on equations 1 and 2. Furthermore, the absorptivity values $\mathrm{E}(1 \%, 1 \mathrm{~cm})$ were determined for the piperine and curcumin at their maximum wavelength.

$$
\begin{aligned}
& \mathrm{Cc}=\frac{(\mathrm{A} 2 \cdot \mathrm{ap} 1)-(\mathrm{A} 1 \cdot \mathrm{ap} 2)}{(\mathrm{ac} 2 \cdot \mathrm{ap} 2)-(\mathrm{ac} 1 \cdot \mathrm{ap} 2)} \\
& \mathrm{Cp}=\frac{(\mathrm{A} 1 \cdot \mathrm{ac} 2)-(\mathrm{A} 2 \cdot \mathrm{ac} 1)}{(\mathrm{ac} 2 \cdot \mathrm{ap} 2)-(\mathrm{ac} 1 \cdot \mathrm{ap} 2)}
\end{aligned}
$$

equation 1

equation 2

Cc: curcumin concentration

Cp: piperine concentration

A1: absorbance measured at $\lambda 335.5 \mathrm{~nm}$

A2: absorbance measured at $\lambda 430.0 \mathrm{~nm}$

Ac1: curcumin absorptivity at $\lambda 335.5 \mathrm{~nm}$ in absorbance/ppm

Ac2: curcumin absorptivity at $\lambda 430.0 \mathrm{~nm}$ in absorbance/ppm

Ap1: piperine absorptivity at $\lambda 335.5 \mathrm{~nm}$ in absorbance/ppm

Ap2: piperine absorptivity at $\lambda 430.0 \mathrm{~nm}$ in absorbance/ppm

\section{Method Validation}

The spectroscopic method for quantification of curcumin and piperine in the same solution was validated according Q2R1 ICH guidelines, which are linearity, accuracy and precision, Limit Of Detection (LOD) and Limit Of Quantification (LOQ) ${ }^{24}$ Linearity between concentrations and absorbance was assessed by analyzing the series concentration of calibration plot using Least Square Analysis. Correlation coefficient (r) of $>0.99$ was used to determine the linearity. ${ }^{25}$ For accuracy and precision studies, three different concentrations of curcumin and piperine in a mixture solution were prepared. Nine different samples were prepared at concentrations of $1,2,4 \mu \mathrm{g} / \mathrm{mL}$ curcumin and $0.5,1,2 \mu \mathrm{g} / \mathrm{mL}$ piperine in the dissolution medium. Accuracy was expressed as recovery value while precision was reflected by relative standard deviation (RSD) value. Inter-day precision and accuracy were determined at another 2 consecutive days. RSD were obtained by dividing the standard deviation with the mean value of obtained concentrations x $100 \%$. Recovery was calculated by ratio of obtained concentration to the accordingly nominal concentration $\times 100 \%$. Linearity, accuracy and precision were judged according to AOAC requirements. ${ }^{25} \mathrm{LOD}$ and LOQ were determined based on standard deviation of response and slope as described previously. ${ }^{26} \mathrm{LOD}$ and LOQ were defined as $3.3 \sigma / \mathrm{S}$ and $10 \sigma / \mathrm{S}$, respectively, where $\sigma$ is the standard error of intercept and $S$ represents the mean of slopes as determined by the Least Square Analysis.

\section{Application of the validated method}

The validated method was applied to quantify curcumin and piperine concentrations after dissolution of a solid dispersion formulation containing both components. The solid dispersion were prepared by spray drying method using polyvinylpyrrolidon K30 (PVP K30) as carrier. The solid dispersion contained $30 \mathrm{wt}-\%$ curcuminoid, $1 \mathrm{wt}-\%$ piperine. In brief, curcumin, piperine and PVP K30 were dissolved in ethanol then spray dried using Büchi B-290 spray dryer equipped with a B-295 dehumidifier. Atomizing air was set at a flow $600 \mathrm{Ln} / \mathrm{h}$. Inlet temperature and aspirator was set at $100^{\circ} \mathrm{C}$ and $100 \%$, respectively. These setting resulted in an outlet temperature of $49-55^{\circ} \mathrm{C}$.

The obtained spray dried powder were weighed accurately (100.00 mg) and then dissolved in $25.0 \mathrm{~mL}$ dissolution medium. A volume of $40 \mu \mathrm{L}$ 
was taken and diluted to $5.0 \mathrm{~mL}$ to achieve final concentrations of curcumin and piperine of 9.60 and $0.32 \mathrm{ug} / \mathrm{mL}$. The absorbance of the diluted sample was measured at 335.5 and $430 \mathrm{~nm}$ for piperine and curcumin, respectively. The measurement was done in triplicate. The concentration of curcumin and piperine was calculated using equation 1 and 2 .

\section{RESULTS}

\section{Spectral Scanning}

Spectral scanning of curcumin, piperine and the mixture of curcuminpiperine solution are presented in Figure 1. In the methanolic solutions (Figure 1a), $\lambda_{\max }$ of single compound of curcumin and piperine appeared to be $420.5 \mathrm{~nm}$ and $341 \mathrm{~nm}$, respectively. Slight bathochromic shifts were observed when curcumin-piperine was co-mixed to 421 and $345 \mathrm{~nm}$ for curcumin and piperine, respectively. When medium dissolution was used to dissolve curcumin or piperine (Figure $1 \mathrm{~b}$ ), $\lambda_{\max }$ of curcumin solution appeared to be bathochromic shifted to 430 with respect to $\lambda_{\max }$ of its methanolic solution ( $420.5 \mathrm{~nm})$. Single piperine solution in medium dissolution appeared to exhibit a hypsochromic shift $(335.5 \mathrm{~nm})$ when compared to its methanolic solution $(341.5 \mathrm{~nm})$. A slight bathochromic shift was observed in a co-mixed curcumin-piperine in dissolution medium from its single piperine solution in dissolution medium (Figure 1b). From the scanning peaks data (Figure 1b) it is obvious that there was no interference of piperine peak at the $\lambda_{\max }$ of curcumin. However, when the piperine concentration was determined using $\lambda_{\max }$ of $335.5 \mathrm{~nm}$, curcumin did interfere significantly. Our data showed that curcumin demonstrates significant absorbance at 0.05 at $\lambda_{\max }$ of 535.5 $\mathrm{nm}$ when the mixture was prepared at ratio curcumin: piperine 1:1 (Figure 1a and 1b). Therefore, to minimize or to avoid the interference of other compound in the determination of piperine concentrations, calculation based on combinatorial equations as presented in equation 2 has to be conducted.

\section{Method validation}

The validation of the spectroscopic method for determination of curcumin-piperine in a dissolution sample followed the procedures as described by $\mathrm{ICH} .{ }^{24}$

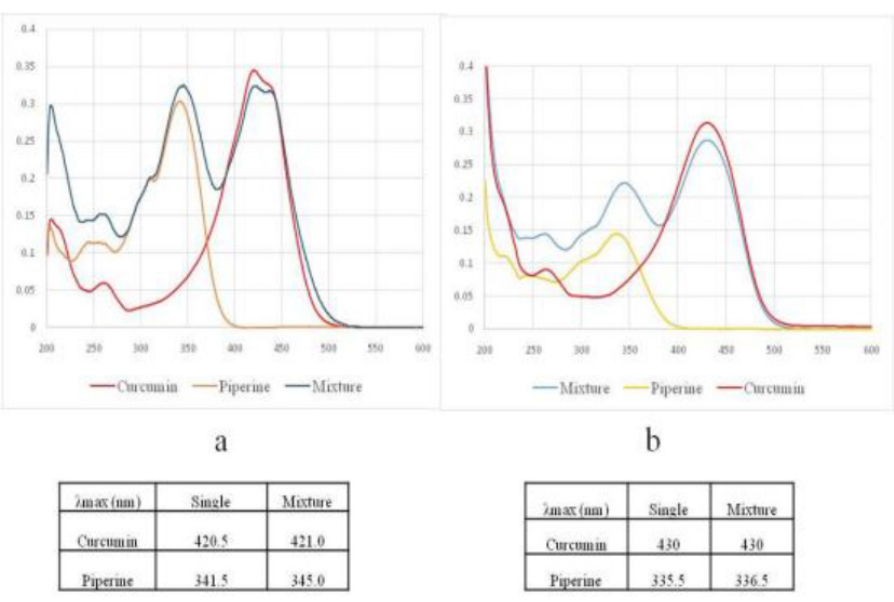

Figure 1: Spectral of curcumin, piperine and curcumin-piperine mixture prepared in methanol (a) and dissolution medium (b). Maximum wavelength shifts were observed when curcumin or piperine or the mixture of both were dissolved in dissolution medium.

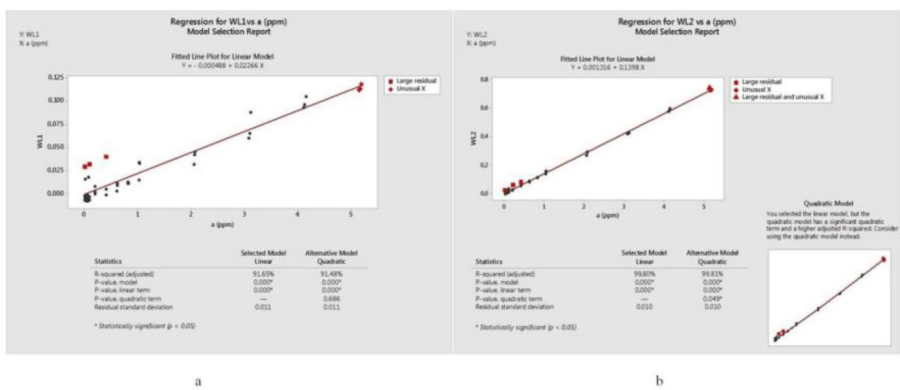

Figure 2: Regression analysis of curcumin concentrations (ppm) vs absorbance at wavelength 1 (a) and 2 (b) with $n=3$.

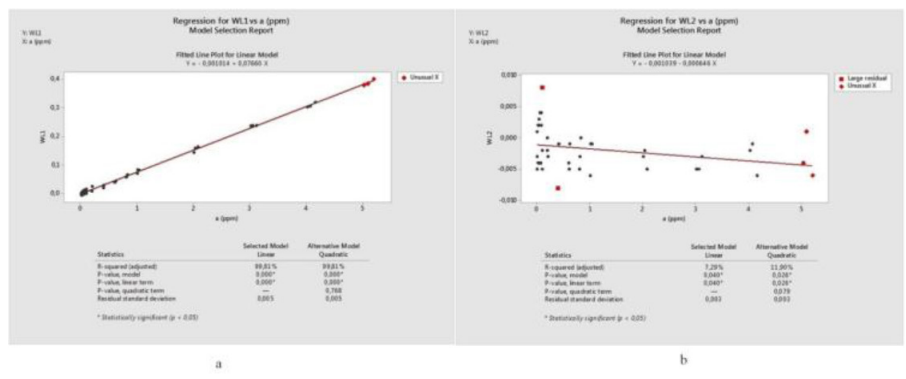

Figure 3: Regression analysis of piperine concentrations (ppm) vs absorbance at wavelength 1 (a) and 2 (b) with $n=3$.

Table 1: Validation parameters for curcumin and piperine prepared in dissolution medium $(n=3)$.

\begin{tabular}{ccc}
\hline Parameter & Curcumin & Piperine \\
\hline$\lambda_{\max }(\mathrm{nm})$ & 430.0 & 335.5 \\
Linear equation & $\mathrm{y}=0.02266 \mathrm{x}-0.00049$ & $\mathrm{y}=0.076598 \mathrm{x}-0.001014$ \\
Slope & 0.139807 & 0.076598 \\
$\mathrm{R}^{2}$ & 0.9980 & 0.9982 \\
$\mathrm{r}$ & 0.9989 & 0.9990 \\
$\mathrm{LOD}(\mu \mathrm{g} / \mathrm{mL})$ & 0.23 & 0.23 \\
$\mathrm{LOQ}(\mu \mathrm{g} / \mathrm{mL})$ & 0.72 & 0.69 \\
\hline
\end{tabular}

\section{Linearity and range}

The calibration curve obtained was evaluated by its correlation coefficient ( $\mathrm{r}$ ) and coefficient of determination $\left(\mathrm{R}^{2}\right)$. To construct calibration curves, 17 different concentrations of co-mixed of curcumin and piperine were prepared in dissolution medium. The concentrations ranged from $0.005-5 \mu \mathrm{g} / \mathrm{mL}$. The calibration curves of curcumin and piperine are depicted in Figure 2 and Figure 3. Linearity of curcumin or piperine was obtained from 10 different concentrations which ranged from 0.1 to $5.0 \mu \mathrm{g} / \mathrm{mL}$ as indicted by $\mathrm{r}$ and $\mathrm{R}^{2}$ of 0.9989 and 0.9980 , respectively, for curcumin and 0.9990 and 0.9982 , respectively, for piperine solutions (Table 1$).{ }^{25}$ Moreover, regression analysis (Figure 2 and Figure 3 ) shows the regression was significant $(p<0.05)$ which can be used as prediction model for the determination of curcumin and piperine concentration in the co-mixture solution. The LOD and LOQ were calculated based on the calibration curves of curcumin and piperine. The calculated LOD of curcumin and piperine was $0.23 \mu \mathrm{g} / \mathrm{mL}$ and the calculated LOQ values were 0.69 and 0.72 for piperine and curcumin, respectively. 
Murti, et al.: UV-Vis Spectroscopy Method to Determine Curcumin and Piperine in Dissolution Samples

Table 2: Intraday and interday precision and accuracy of piperine $(n=3)$.

\begin{tabular}{ccccccc}
\hline $\begin{array}{c}\text { Nominal concentration } \\
(\mu \mathrm{g} / \mathrm{mL})\end{array}$ & Found $(\mu \mathrm{g} / \mathrm{mL})$ & $\begin{array}{c}\text { Intraday } \\
\text { Precision }(\% \mathrm{RSD})\end{array}$ & $\begin{array}{c}\text { Accuracy } \\
(\% \text { recovery) }\end{array}$ & Found $(\mu \mathrm{g} / \mathrm{mL})$ & $\begin{array}{c}\text { Interday } \\
\text { Precision (\% RSD) }\end{array}$ \\
\hline 0.5 & 0.54 & 1.67 & 107.38 & 0.51 & 2.87 & 102.69 \\
1.0 & 1.02 & 10.7 & 102.00 & 1.01 & 8.82 & 101.00 \\
2.0 & 2.09 & 0.48 & 104.50 & 2.05 & 1.73 & 102.50 \\
\hline
\end{tabular}

Table 3: Intraday and interday precision and accuracy of curcumin $(n=3)$.

\begin{tabular}{ccccccc}
\hline \multirow{2}{*}{$\begin{array}{c}\text { Nominal } \\
\text { concentration } \\
(\mu \mathrm{g} / \mathrm{mL})\end{array}$} & Found $(\mu \mathrm{g} / \mathrm{mL})$ & Precision (\%RSD) & Accuracy (\%recovery) & Found $(\mu \mathrm{g} / \mathrm{mL})$ & Precision (\% RSD) & Accuracy $(\%$ recovery) \\
\cline { 2 - 7 } & 1.03 & 9.64 & 103.00 & 0.99 & 7.29 & 96.84 \\
1.0 & 2.09 & 2.67 & 104.50 & 1.98 & 2.14 & 94.87 \\
2.0 & 4.22 & 5.62 & 105.50 & 4.05 & 3.45 & 95.40 \\
4.0 & & & & &
\end{tabular}

\section{Precision and accuracy}

Precision was evaluated at three different concentrations prepared in dissolution medium, which were $0.5,1$ and $2 \mu \mathrm{g} / \mathrm{mL}$ for piperine and $1,2,4$ $\mu \mathrm{g} / \mathrm{mL}$ for curcumin. Precision and accuracy data are presented in Table 2 and Table 3. Intra-day and inter-day precision study for curcumin and piperine of the method shows RSD values between $0.48-10.70$, which confirms reliability and stability of the method based on AOAC requirements. ${ }^{25}$ Accuracy data as indicated by the recovery values shows recovery of 94-107\% which confirms the validity of the method according to the AOAC requirements. ${ }^{25}$

\section{Application of the validated method}

The validated method was applied to measure the concentration of curcumin and piperine dissolved in the dissolution medium. The sample dilution preparation was conducted as such mimicking the concentration found at the initial time sampling. Considering the dose of $500 \mathrm{mg}$ curcuminoids and $5 \mathrm{mg}$ of piperine in a tablet as conducted in a clinical trial ${ }^{10}$ and of at least $5 \%$ analyte should be released in $1000 \mathrm{~mL}$ of dissolution medium during earlier sampling, it is required to be able to measure concentrations of $25 \mu \mathrm{g} / \mathrm{mL}$ curcumin and $0.25 \mu \mathrm{g} / \mathrm{mL}$ of piperine accurately. Using this validated spectroscopic method, curcumin concentration was found to be $10.11 \pm 0.09 \mu \mathrm{g} / \mathrm{mL}$ with $\mathrm{RSD}$ value of $0.89 \%$ while the piperine concentration was found to be $0.33 \pm 0.06 \mu \mathrm{g} / \mathrm{mL}$ with RSD value of $18.18 \%$. Taking the expected concentrations of 25 and $0.25 \mu \mathrm{g} / \mathrm{mL}$ for curcumin and piperine during initial time sampling and the found concentrations of $10.11 \pm 0.09 \mu \mathrm{g} / \mathrm{mL}$ (curcumin) and $0.33 \pm 0.06 \mu \mathrm{g} / \mathrm{mL}$ (piperine), it can be concluded that this validated spectroscopic method is sensitive enough to simultaneously quantify curcumin and piperine in the dissolution sample. Although we prepared a slightly higher concentration of piperine in the dissolution sample (around $0.32 \mu \mathrm{g} / \mathrm{mL}$ ) than the expected concentration appears in dissolution media $(0.25 \mu \mathrm{g} / \mathrm{mL})$, we were still able to confirm the sensitivity of the method based on the found LOD $(0.23 \mu \mathrm{g} / \mathrm{mL})$. In the sample, the RSD of piperine was quite high, which was $18.18 \%$. The RSD value of piperine was high due to the very low piperine concentration approaching at detection level of the method $(0.23 \mu \mathrm{g} / \mathrm{mL})$.

\section{DISCUSSION}

The aim of this study was to develop and validate a spectroscopic method to determine curcumin and piperine in dissolution samples. As a BCS II drug, dissolution behavior of curcumin and piperine is being the most important predictive parameter for the bioavailability. ${ }^{27}$ In screening of a formula candidate, dissolution behavior of a drug is the most useful parameters, which it may end up with large number of dissolution samples and those need quick analysis to allow rapid selection of formula for bioavailability evaluation.

Analytical method validation objective is to demonstrate suitability and reliability of an analytical procedure for its intended purpose. ${ }^{28}$ This study validated the spectroscopic method to quantify curcumin and piperine in the dissolution medium. The dissolution medium contained $0.5 \mathrm{wt}-\%$ SLS in $20 \mathrm{mM}$ sodium phosphate buffer of $\mathrm{pH}$ 6.0. Sodium phosphate buffer at $\mathrm{pH} 6.0$ was used to confirm curcumin stability during dissolution study, since curcumin was found to be stable at $\mathrm{pH}$ 6.0. ${ }^{6}$ SLS was added in the dissolution medium to attain sink condition. ${ }^{29}$ Although chromatographic methods are found in many publications for accurately determine curcumin-piperine, SLS and sodium phosphate buffer in the dissolution media may cause poor peak separation in chromatographic method. Collier et al. reported that SLS in the dissolution media interferes the chromatographic separation of levothyroxine as indicated by a dramatic decrease in plate counts after number of samples injection into the HPLC column, and that resulted a high variability in drug content in the dissolution samples. ${ }^{30}$ Recently, Setyaningsih et al. found that SLS and sodium phosphate buffer cause peak tailing of curcuminoids resulting poor peak separation. ${ }^{31}$ The interference caused by SLS and sodium phophate buffer leads to jeopardize accurate estimation of curcumin in dissolution samples.

Sample preparation is required to obtain satisfactory chromatographic peaks separations. However, extensive sample preparation, which may involve multiple clean up steps followed by extraction procedures, might raise stability concerns of curcumin. A report from Tonnesen and Karlson suggests that when using buffers and ethyl acetate for extraction, polymerization of curcumin can occur at the interface of the two phases. ${ }^{19}$

Although spectroscopic method has been acknowledged as not selective; there is no ability of the method to determine curcumin from curcuminoids mixture, as these curcuminoids appears to be overlaping in UV spectra at the same wavelength, ${ }^{30}$ the method are still useful to determined curcumin concentration in dissolution study. Despite the selectivity problem, the spectrophotometric method offers simplicity, rapidity and reliability. ${ }^{32,33}$ Being the major component in curcuminoids mixture, curcumin concentration in samples can be determined as total curcumi- 
noids which are present in the dosage forms or polyherbal samples. ${ }^{20}$ Taken all together, spectrophotometry remains valuable method to determine curcumin in the dissolution samples. Furthermore, using combinatorial equation involving absorptivity molar and absorbance of curcumin and piperine (equation 1 and 2), this developed method are able to reliably determine curcumin in co-existence with piperine

This proposed spectroscopic method confirms linearity, accuracy and precision of the method as required by AOAC. The LOD of piperine and curcumin was $0.23 \mu \mathrm{g} / \mathrm{mL}$ and LOQ were 0.69 and 0.72 for piperine and curcumin, respectively. As comparison, when methanol was used to prepare samples, Aneja et.al found LOD of $0.71 \mu \mathrm{g} / \mathrm{mL}$ and $0.45 \mu \mathrm{g} / \mathrm{mL}$ and LOQ of $2.1 \mu \mathrm{g} / \mathrm{mL}$ and $1.49 \mu \mathrm{g} / \mathrm{mL}$ for piperine and curcumin, respectively, ${ }^{21}$ which indicates that this validated method of curcumin/piperine quantification in dissolution medium is more sensitive compared to the previous report.

\section{CONCLUSION}

The UV-Vis spectroscopy method is accurate, precise and reliable to be used for the quantification of curcumin and piperine in dissolution medium composed of $0.5 \mathrm{wt}-\%$ SLS in $20 \mathrm{mM}$ sodium phosphate buffer of $\mathrm{pH} 6.0$ where curcumin and piperine are co-present. Moreover, the LOD shows to be sensitive. Thus validation confirmed that the method is applicable for the determination of curcumin or piperine during dissolution studies.

\section{ACKNOWLEDGEMENT}

This study is fully supported by the Ministry of Research, Technology and Higher Education of Republic Indonesia through the scheme of International Research Collaboration and Scientific Publication year of 2018 (3/E/KPT/2018).

\section{CONFLICT OF INTEREST}

The authors declare no conflict of interest.

\section{ABBEVIATION}

BCS: Biopharmaceutical classification system; LOD: Limit of detection; LOQ: Limit of Quantification; RSD: Relative standard deviation; SLS: Sodium lauryl sulfete; UV-Vis: Ultraviolet-visible.

\section{REFERENCES}

1. Aggarwal B, Surh YJ, Shishodia S, Menon V, Sudheer A. Antioxidant and antiinflammatory properties of curcumin. The Molecular Targets and Therapeutic Uses of Curcumin in Health and Disease: Springer US. 2007;105-25.

2. Kapoor S. Curcumin and Its Emerging Role in Pain Modulation and Pain Management. Korean J Pain. 2012;25(3):202-3.

3. Abdollahi E, Momtazi AA, Johnston TP, Sahebkar A. Therapeutic effects of curcumin in inflammatory and immune-mediated diseases: A nature-made jackof-all-trades?. J Cell Physiol. 2017. http://dx.doi.org/10.1002/jcp.25778

4. Siviero A, Gallo E, Maggini V, Gori L, Mugelli A, Firenzuoli F, et al. Curcumin, a golden spice with a low bioavailability. J Herb Med. 2015;5(2):57-70.

5. Hatcher $\mathrm{H}$, Planalp R, Cho J, Torti FM, Torti SV. Curcumin: From ancient medicine to current clinical trials. Cell Mol Life Sci. 2008;65(11):1631-52.

6. Wang $Y J$, Pan MH, Cheng AL, Lin LI, Ho YS, Hsieh $C Y$, et al. Stability of curcumin in buffer solutions and characterization of its degradation products. J Pharm Biomed Anal. 1997;15(12):1867-76.

7. Wahlström B, Blennow G. A study on the fate of curcumin in the rat. Acta Pharmacol Toxicol. 1978;43(2):86-92.

8. Holder GM, Plummer JL, Ryan AJ. The metabolism and excretion of curcumin (1,7-bis-(4-hydroxy-3-methoxyphenyl)-1,6-heptadiene-3,5-dione) in the rat. Xenobiotica. 1978;8(12):761-8.

9. Riswan S, Sangat-Roemantyo H. Jamu as traditional medicine in Java, Indonesia.
South Pacific Study. 2002;23(1):1-10

10. Shoba G, Joy D, Joseph T, Majeed M, Rajendran R, Srinivas PS. Influence of Piperine on the Parmacokinetics of Curcumin in Animals and Human Volunteers. Planta Med. 1998;64(4):353-6

11. Volak LP, Ghirmai S, Cashman JR, Court MH. Curcuminoids inhibit multiple human cytochromes P450, UDP-glucuronosyltransferase and sulfotransferase enzymes, whereas piperine is a relatively selective CYP3A4 inhibitor. Drug Metab Dispos. 2008;36(8):1594-605.

12. Zhou S, Lim LY, Chowbay B. Herbal modulation of P-glycoprotein. Drug Metab Rev. 2004;36(1):57-104

13. Srinarong $P$, de Waard $H$, Frijlink HW, Hinrichs WL. Improved Dissolution Behavior of Lipophilic Drugs by Solid Dispersions: the Production Process as Starting Point for Formulation Considerations. Expert Opin Drug Deliv. 2011;8(9):1121-40.

14. Tu YS, Fu JW, Sun DM, Zhang JJ, Yao N, Huang DE, et al. Preparation, characterisation and evaluation of curcumin with piperine-loaded cubosome nanoparticles. J Microencapsulation. 2014;31(6):551-9

15. Moorthi C, Krishnan K, Manavalan R, Kathiresan K. Preparation and characterization of curcumin-piperine dual drug loaded nanoparticles. Asian Pac J Trop Biomed. 2011;2(11):841-8.

16. Grill A, Koniar B, Panyam J. Co-delivery of natural metabolic inhibitors in a self-microemulsifying drug delivery system for improved oral bioavailability of curcumin. Drug Deliv Trans Res. 2014;4(4):344-52

17. Ramaswamy S, Kuppuswamy G, Dwarampudi P, Kadiyala M, Menta L, Kannan E. Development and validation of simultaneous estimation method for curcumin and piperine by RP-UFLC. Pak J Pharm Sci. 2014;27(4):901-6.

18. Verma J, Joshi A. Rapid HPTLC method for identification and quantification of curcumin, piperine and thymol in an ayurvedic formulation. JPC J Planar Chromat. 2006;19(111):398-400

19. Tonnesen $H$, Karlsen J. Studies on curcumin and curcuminoids VI. Kinetics of curcumin degradation in aqueous solution. Z Lebensm Unters Forsch. 1985; 180(5):402-4.

20. Singh A, Avupati VR. Development and Validation of UV-Spectrophotometric method for the Estimation of Curcumin in Standardised Polyherbal Formulations. J Young Pharm. 2017:9(4):491-5.

21. Aneja G, Dave U, Vadodaria K. Simultaneous Estimation of Piperine, Quercetin and Curcumin in A Mixture Using UV-Visible Spectrophotometer and Method Validation. IJTA. 2012;8:14-7.

22. Shingate PN, Dongre PP, Kannur DM. New Method Development for Extraction and Isolation of Piperine from Black Pepper. International JPSR. 2013;4(8):3165-70.

23. Saha KC, Seal HP, Noor MA. Isolation and characterization of piperine from the fruits of black pepper (Piper nigrum). J Bangladesh Agril Univ. 2013;11(1):11-6.

24. International Conference on Harmonization $(\mathrm{ICH})$. ICH Harmonised tripartite guideline. Validation of analytical procedures: Text and methodology ed: Geneva. 2005.

25. The Association of Official Analytical Chemists (AOAC). Official Methods of Analysis of AOAC Interntional. In: George W. Latimer J, editor. Guidelines for Standard Method Performance Requirements. $19^{\text {th }}$ ed. Gaithersburg, Maryland, USA: AOAC International. 2012;9.

26. González G, Herrador A. A practical guide to analytical method validation including measurement uncertainty and accuracy profiles. Trends Analyt Chem 2007;26(3):227-38.

27. Hu L, Shi Y, Li JH, Gao N, Ji J, Niu F, et al. Enhancement of Oral Bioavailability of Curcumin by a Novel Solid Dispersion System. AAPS PharmSciTech. 2015;16(6):1327-34

28. Food and Drug Administration (FDA). Analytical Procedures and Methods Validation for Drugs and Biologics-Guidance for Industry. Division of Drug Information Center for Drug Evaluation and Research Food and Drug Administration. 2015;1-13

29. Visser MR, Baert L, Klooster G, Schueller L, Geldof M, Vanwelkenhuysen I, et al. Inulin solid dispersion technology to improve the absorption of the BCS Class IV drug TMC240. Eur J Pharm Biopharm. 2009;74(2):233-8.

30. Collier JW, Shah RB, Bryant AR, Habib MJ, Khan MA, Faustino PJ. Development and application of a validated HPLC method for the analysis of dissolution samples of levothyroxine sodium drug products. J Pharm Biomed Anal. 2011;54(3):433-8.

31. Setyaningsih D, Murti YB, Fudholi A, Hinrichs WLJ, Mudjahid R, Martono S, et al. Validated TLC Method for Determination of Curcumin Concentrations in Dissolution Samples Containing Curcuma longa Extract. JIFI. 2016;14(2):147-57.

32. Sharma K, Agrawal SS, Gupta M. Development and validation of UV spectrophotometric method for the estimation of curcumin in bulk drug and pharmaceutical dosage forms. Int J Drug Dev and Res. 2012;4(2):375-80.

33. Mazzarino L, Bellettini IC, Minatti E, Lemos-Senna E. Development and validation of a fluorimetric method to determine curcumin in lipid and polymeric nanocapsule suspensions. Braz J Pharm Sci. 2010:46(2):219-26.

Article History: Submission Date : 15-11-2018; Revised Date : 30-11-2018; Acceptance Date : 05-12-2018

Cite this article: MurtiYB, HartiniYS, Hinrichs WLJ, Frijlink HW, Setyaningsin D. UV-Vis Spectroscopy to Enable Determination of the Dissolution Behavior of Solid Dispersions Containing Curcumin as Well as Piperine. J Young Pharm. 2019;11(1):26-30 